\title{
Oligothiophene-Containing Polymer Brushes by ROMP and RAFT: Synthesis, Characterization and Dielectric Properties
}

Yali Qiao, ${ }^{\dagger}$ Md. Sayful Islam, ${ }^{\dagger}$ Xiaodong Yin,${ }^{\dagger}$ Kuo Han,${ }^{\S}$ Yi Yan, ${ }^{\dagger}$ Jiuyang Zhang,${ }^{\dagger}$ Qing Wang ${ }^{\S}$ Harry J. Ploehn,${ }^{\ddagger}$ Chuanbing Tang* ${ }^{\dagger}$

${ }^{\dagger}$ Department of Chemistry \& Biochemistry, University of South Carolina, Columbia, South Carolina 29208, USA

${ }^{\ddagger}$ Department of Chemical Engineering, University of South Carolina, Columbia, South Carolina 29208, USA

${ }^{\S}$ Department of Material Science and Engineering, Pennsylvania State University, University Park, Pennsylvania 16802, USA

Corresponding Author E-mail: tang4@mailbox.sc.edu (CT)

\section{Dedicated to Professor Krzysztof Matyjaszewski on his 65th birthday.}

\begin{abstract}
We report the synthesis of oligothiophene-containing polymer brushes and their application as nanodielectric materials in capacitors. Specifically, terthiophene-containing methacrylate polymer brushes were synthesized via a "graft from" technique by a combination of ring-opening metathesis polymerization (ROMP) and reversible addition fragmentation chain transfer (RAFT) polymerization. Both X-ray scattering and thermal studies indicated that polymer brushes led to the formation of small nanoscale crystalline domains $(\sim 2 \mathrm{~nm})$ dispersed in an amorphous matrix. Notably, the film forming capability and processability are greatly improved in comparison with corresponding homopolymers. Transparent free-standing films could be readily
\end{abstract}


fabricated based on these polymer brushes and used for dielectric property studies. The adoption of polymer brush architecture into the oligothiophene-containing polymers has been proved to be an effective strategy to improve the mechanical robustness of films.

Keywords: Terthiophene, polymer brushes, nanodielectric materials, capacitor

\section{Introduction}

Novel dielectric materials with superior energy storage capability have attracted great interest due to their potential applications as capacitor materials in portable electronic devices, power electronics for grid energy management, and pulsed power systems. ${ }^{1-4}$ Generally, dielectric materials useful for energy storage require large relative permittivity, high breakdown field strength, and low dielectric loss, especially at high frequencies ( 1 MHz). ${ }^{5}$ Traditionally, high performance dielectric materials are inorganic ceramics, ${ }^{6-9}$ which have high dielectric permittivity, but low breakdown strength and high dielectric loss, limiting their energy density and thus practical application for pulse power capacitors. On the contrary, polymers can offer high breakdown strength and low dielectric loss with better mechanical properties, facile processability, and lighter weight. Thus, polymers ${ }^{5}$ and polymer composites ${ }^{10,11}$ have been extensively investigated as alternative dielectric materials for pulse power applications. ${ }^{12-15}$ However, most polymers possess low permittivities (e.g. $\varepsilon_{\mathrm{r}}=2-3$ ) compared to dielectric inorganic ceramics. Besides, although ferroelectric poly(vinylidene fluoride) (PVDF)-based polymers (and polymer composites) can offer relatively high permittivity (e.g. > 10 for PVDF at $1 \mathrm{KHz}$ ), ${ }^{16-18}$ they usually exhibit high dielectric loss, especially at high frequencies, limiting their usefulness as dielectric materials in capacitors for energy storage and pulse power applications. Therefore, high performance dielectric polymers that can overcome the limitations of existing polymer dielectrics are needed as capacitor materials for power electronics and 
pulse power applications.

There are many approaches for the development of high performance polymer dielectrics, including high permittivity polymer blends ${ }^{19-25}$ and all-polymer percolative dielectric composites. ${ }^{26-33}$ We have recently explored a new approach to developing polymer dielectrics by adopting a "nanodielectric" concept. ${ }^{34-39}$ In our approach, we develop interfacially-dominated dielectric materials that store energy through electronic conduction and interfacial polarization. Briefly, we take advantage of nanophase separation in polymers that are composed of both conductive and insulating moieties. Upon spontaneous nanophase segregation, the conductive moiety can form nanoscale domains with high electronic conductivity, while the other insulating moiety can separate the conducting domains to prevent percolation and inter-domain conduction. When an electric field is applied, electronic conduction results in space charge accumulation and local dipole formation along the phase boundaries. Considering the nanoscale conducting domain size, the substantial interfacial area between phases leads to dielectric materials with energy storage dominated by interfacial polarization. We believe that such nanodielectric polymers will overcome the limitations of existing polymer dielectrics and meet the requirements for next-generation polymer dielectrics as capacitor materials for power electronics and pulse power applications.

We recently developed a series of nanophase-separated $\pi$-conjugated oligomer-containing polymers as novel dielectric materials. ${ }^{37}$ Specifically, we have designed terthiophene-containing methacrylate polymers (PTTEMA), in which the oligothiophene-based side chains self-organize into nanoscale conjugated, crystalline, electrically-conductive domains $(<2 \mathrm{~nm})$ and disperse in an insulating amorphous polymer matrix consisting of the methacrylate polymer main chain. PTTEMA polymers exhibit high dielectric permittivity and low loss $\left(\varepsilon_{\mathrm{r}}>10\right.$, and $\left.\tan \delta<0.02\right)$ with an excellent consistency over a wide frequency range $(100 \mathrm{~Hz}-4 \mathrm{MHz})$. 
However, there are still a myriad of challenging issues facing PTTEMA homopolymers. Especially, the brittle nature of PTTEMA homopolymer based films is one of the most intractable problems, which not only limits the film-making processes, but also has a negative effect on the dielectric performance (e.g., breakdown strength, energy loss). Herein we introduce a polymer brush architecture for incorporating such nanophase-separated $\pi$-conjugated oligomer-containing polymers. The goal is to modify the film quality and/or processability in order to optimize the dielectric performance. Unlike homopolymers, polymer brushes can offer considerably high molecular weight. Also, the high grafting density of PTTEMA side chains along the backbone could lead to more interactions in the side chain. All these merits might be beneficial to improve mechanical properties, and thus to achieve better film quality/ processability and good dielectric performance.

Controlled polymerization is an effective tool to construct a wide spectrum of polymers with rich topologies, including polymer brushes. ${ }^{40-48}$ Prof. Krzysztof Matyjaszewski is one of the pioneers and giants in the modern polymer science to build the foundation of controlled polymerization. Specifically, we will prepare a series of terthiophene-containing polymer brushes via a "grafting from" technique by a combination of ring-opening metathesis polymerization (ROMP) and reversible addition fragmentation chain transfer (RAFT) polymerization. The thermal properties and crystalline structure of polymer brushes are fully characterized. Transparent free-standing films based on the oligothiophene-containing polymer brushes were successfully fabricated. Dielectric properties are also investigated based on the free-standing films using both low voltage impedance spectroscopy and high voltage polarization measurements.

\section{Experimental section}




\subsection{Materials}

4-Cyano-4-(phenylcarbonothioylthio)pentanoic acid (97\%, CPPA) and ethyl vinyl ether (99\%) were purchased from Aldrich and used directly. $\mathrm{N}$-[3-hydroxylpropyl]-cis-5-norbornene-exo-2,3-dicarboximide $(\mathrm{NPH})$, N-[4-Cyano-4-(phenylcarbonothioylthio)-pentanoate]-cis-5-norbornene-exo-2,3-dicarbox imide (N-CPPA) and monomer 2-([2,2':5',2"-terthiophen]-5-yl)ethyl methacrylate (TTEMA) were synthesized according to our earlier reports. ${ }^{37,49-51}$ Grubbs III catalyst was synthesized following a procedure reported in the literature. ${ }^{52} 1,4$-Dioxane was dried over sodium and freshly distilled before use. All other reagents were purchased from commercial sources and used as received unless otherwise noted.

\subsection{Characterization}

${ }^{1} \mathrm{H}$ NMR (300 MHz) spectra were recorded on a Varian Mercury 300 spectrometer with tetramethylsilane (TMS) as an internal reference. Gel permeation chromatography (GPC) was performed at $50{ }^{\circ} \mathrm{C}$ on a Varian system equipped with a Varian 356-LC refractive index detector and a Prostar 210 pump. The columns were STYRAGEL HR1, HR2 (300 $\times 7.5 \mathrm{~mm}$ ) from Waters. HPLC grade DMF with $0.01 \mathrm{wt} \% \mathrm{LiBr}$ was used as eluent at a flow rate of $1.0 \mathrm{~mL} / \mathrm{min}$. Polystyrene standards were used for calibration. Mass spectrometry was conducted on a Waters Micromass Q-Tof mass spectrometer, and the ionization source was positive ion electrospray. Thermal transitions of the polymers were recorded by using differential scanning calorimetry (DSC) on a TA Instruments Q2000 in a temperature range from 0 to $200{ }^{\circ} \mathrm{C}$ at heating and cooling rates of $10{ }^{\circ} \mathrm{C} \mathrm{min}{ }^{-1}$ under

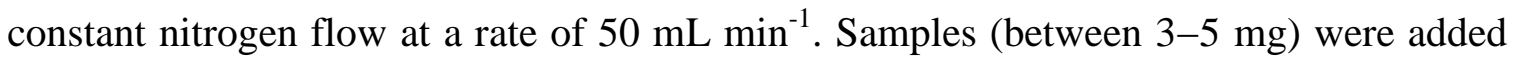
to aluminum hermetic pans and sealed. The data were collected during the second heating and cooling cycle. Thermogravimetric analysis (TGA) was conducted on a TA Instruments Q5000 using a heating rate of $10{ }^{\circ} \mathrm{C} \min ^{-1}$ from RT to $1000{ }^{\circ} \mathrm{C}$ under 
constant nitrogen flow. X-ray diffraction (XRD) measurements were conducted on a Rigaku D/Max 2100 Powder X-Ray Diffractometer ( $\mathrm{Cu} K \alpha$ radiation) instrument. Tapping Mode Atomic Force Microscopy (AFM) experiments were carried out using a Multimode Nanoscope V system (Bruker, Santa Barbara, CA). The measurements were performed using commercial Si cantilevers with a nominal spring constant and resonance frequency at $20-80 \mathrm{~N} / \mathrm{m}$ and $230-410 \mathrm{kHz}$, respectively (TESP, Bruker AFM Probes, Santa Barbara, CA). The thin films based on PNB-g-PTTEMA polymer brushes for AFM imaging were prepared as follows: $0.05 \mathrm{~g} \mathrm{~mL}^{-1}$ solution of each sample in 1,2-dichlorobenzene was drop-cast on silicon wafers, and the films were then thermally dried at room temperature overnight.

\subsection{Dielectric Properties}

Films for dielectric property characterization were prepared by a hot-press process. The specimens were fabricated by pressing the polymer on aluminum pan at $145-150{ }^{\circ} \mathrm{C}$, which resulted in films with uniform thickness and free of bubbles, cracks, or other defects. Film thicknesses were measured at multiple positions with a micrometer, in the range of $30-40 \mu \mathrm{m}$. Strips of aluminum pan bearing polymer brush films were cut using scissors; the aluminum pan served as the bottom electrode for dielectric measurements. Gold was sputter-coated under argon atmosphere through a shadow mask to deposit circular gold electrodes (area $0.282 \mathrm{~cm}^{2}$ ) on the films' surfaces.

The films' complex impedance was measured at varying frequency (typically $10^{2} \mathrm{~Hz}$ to 1.2 MHz) using an impedance analyzer (Agilent model 4192A LF). Impedance spectra were collected for 3-5 specimens of each sample to ensure reproducibility; average values are reported. The real and complex parts of the impedance, expressed as impedance magnitude and phase angle, were analyzed using a parallel RC circuit model 
describing a "leaky" capacitor, yielding values of relative permittivity $\left(\varepsilon_{\text {eff }}\right)$ and loss tangent $(\tan \delta)$ as functions of frequency.

\subsection{Electric Displacement-Electric Field $(D-E)$ Loops}

Free-standing films for $D-E$ loops were prepared by a hot-press process. The polymer powder was placed on a preheated hot plate at $145-150{ }^{\circ} \mathrm{C}\left(20-25{ }^{\circ} \mathrm{C}\right.$ above their respective melting temperatures) in a hydraulic press, using Kapton films as substrates. The pressure was increased by 250 psi every 15 minutes up to $1500 \mathrm{psi}$. The films were kept at 1500 psi for another ten minutes to ensure film uniformity. The films were then removed from the press and allowed to air cool to room temperature. Finally, the free-standing films were peeled off from the Kapton films. Film thicknesses varied between $30-40 \mu \mathrm{m}$. The polymer films were sputter-coated with gold on both sides and then used for the $D-E$ loop measurements. Polarization measurements employed a Precision Multiferroic polarization tester (Radiant, Inc.). Polarization data ( $D$ versus $E$ ) were obtained for applied voltages up to $4000 \mathrm{~V}$ with a cycle frequency of $1.0 \mathrm{kHz}$. The maximum applied field strength depended on the sample film thickness and breakdown $\mathrm{s}$, was determined by numerical integration of $E$, according to $\bar{W}=\int E d D$, from $D=0$ to the maximum value of $D\left(D_{\max }\right)$ achieved in the hysteresis loop. Recovered energy density $\left(\hat{W}_{r}\right)$ was determined by numerically integrating $E$ from $D_{\max }$ to the value of $D$ where $E=0$. Percentage energy loss is computed as $100 \times\left(\hat{W}_{s}-\widehat{W}_{r}\right) / \bar{W}_{s}$.

\subsection{General Procedure for Synthesis of PN-g-PTTEMA Polymer Brushes}

Macroinitiator PN-CPPA: Followed our previous report, ${ }^{37}$ PN-CPPA was prepared via ROMP. N-CPPA was dissolved in dry DCM and then added into a Grubbs III catalyst solution in DCM. The reaction was conducted at room temperature under ambient 
atmosphere. The conversion of monomers was monitored by ${ }^{1} \mathrm{H}$ NMR by comparing the integration of peaks at $\sim 6.24 \mathrm{ppm}$ with peaks at $7.40-8.00 \mathrm{ppm}$. The reaction was stopped after 8 min with a conversion of around $60-70 \%$. The mixture was precipitated in diethyl ether three times, vacuum-dried to yield red polymers. The degree of polymerization was determined by conversion with ${ }^{1} \mathrm{H}$ NMR (DP = 127). $M_{\mathrm{n}}(\mathrm{NMR})$ : $61,300 \mathrm{~g} \mathrm{~mol}^{-1} \cdot M_{\mathrm{n}}(\mathrm{GPC}): 123,200 \mathrm{~g} \mathrm{~mol}^{-1}, \nexists: 1.20$ (GPC). The corresponding ${ }^{1} \mathrm{H}$ NMR and GPC results are in Supporting Information (Figures S1 and S2).

PNB-g-PTTEMA Polymer Brushes: A mixture of monomer TTEMA, macroinitiator PN-CPPA, and AIBN with predetermined ratios (e.g., for $\mathrm{PN}_{127} g-\mathrm{PTTEMA}_{29}$, [TTEMA]:[PN-CPPA]:[AIBN] = 100:1:0.3) were dissolved in dry 1,4-dioxane, and added to a $10 \mathrm{~mL}$ Schlenk flask and degassed by 5 cycles of freeze-pump-thaw. An initial sample was taken before the flask was submerged into an $80{ }^{\circ} \mathrm{C}$ preheated oil bath. Samples were taken out at predetermined intervals to monitor the reaction conversion by ${ }^{1} \mathrm{H}$ NMR before stopping the reaction. When conversion reached a targeted value (e.g., for $\mathrm{PN}_{127-} g-\mathrm{PTTEMA} 29$, targeted conversion is ca. $29 \%$ ), the reaction was immediately quenched in ice bath, and the mixture was diluted with THF. The terthiophene-containing polymer brush was purified by precipitation into cold hexane three times to remove any unreacted TTEMA monomers, and vacuum dried at room temperature, yielding a light yellow powder. The degree of polymerization for grafted PTTEMA was determined from conversion by ${ }^{1} \mathrm{H}$ NMR (e.g., for $\mathrm{PN}_{127}-g$-PTTEMA 29 , DP $=29$ for grafted PTTEMA), and the molecular weight $\left(M_{\mathrm{n}}\right)$ of PN-g-PTTEMA polymer brushes could be calculated from DP of polymer backbone and grafted side-chains (e.g., for PN $_{127^{-}} g$-PTTEMA $29, M_{\mathrm{n}}$ $=1.389,100 \mathrm{~g} / \mathrm{mol}$ ). Because the molecular weight of polymer brushes is too high, GPC characterization was not accurate. However, molecular brushes could be observed by AMF imaging. Moreover, all the corresponding integral peaks from PTTEMA side-chains could be clearly assigned by ${ }^{1} \mathrm{H}$ NMR (see Figure 1). These results 
confirmed the successful synthesis of polymer brushes. ${ }^{1} \mathrm{H}$ NMR $\left(300 \mathrm{MHz}, \mathrm{CDCl}_{3}\right): \delta$ (ppm) 7.50-7.75 (broad, Ph from RAFT agent end group), 6.25-7.25 (m, aromatic proton from terthiophene), $4.05\left(\mathrm{~s},-\mathrm{CH}_{2} \mathrm{O}-\right.$ from PTTEMA side-chains), $2.80\left(\mathrm{~s},-\mathrm{CH}_{2^{-}}\right.$in PTTEMA side-chains), $1.50-2.05$ (m, $-\mathrm{CH}_{2^{-}}$in PTTEMA backbone), $0.50-1.01$ (m, $\left.-\mathrm{CH}_{3}\right)$.

\section{Results and discussion}

\subsection{Synthesis and Characterization}

We prepared the first oligothiophene-containing molecular brushes via a "grafting from" technique by a combination of ROMP and RAFT polymerization, as shown in Scheme 1. According to previous reports, ${ }^{49-51}$ a norbornene-functionalized chain transfer agent (N-CPPA) was first synthesized as a monomer, followed by ROMP to produce the brush polymer backbone PN-CPPA. All proton peaks from polynorbornene and CPPA were well assigned in ${ }^{1} \mathrm{H}$ NMR (Figure S1), which confirmed the successful synthesis of the polymer backbone PN-CPPA. GPC result showed a low dispersity $\oslash=1.20$ (Figures S2), indicating the well-controlled nature of ROMP. Then, a terthiophene-containing methacrylate monomer (TTEMA) was polymerized from the backbone via RAFT, yielding the final polymer brush PN-g-PTEEMA. Two polymer brushes with side chain PTTEMA of different degrees of polymerization were prepared. GPC could not be accurately determined for both polymer brushes due to their molecular weight higher than our reliable calibration limit. However, NMR spectra can confirm the successful synthesis of the polymer brushes. Figure 1 shows the representative ${ }^{1} \mathrm{H}$ NMR spectrum

for polymer brush $\mathrm{PN}_{127}-g-\mathrm{PTTEMA}_{29}\left(\right.$ see ${ }^{1} \mathrm{H}$ NMR spectrum for $\mathrm{PN}_{127}-g-\mathrm{PTTEMA}_{38}$ in Figure S3). All protons from the TTEMA monomer can be clearly assigned. The degree of polymerization (DP) for both PN backbone and side chain PTTEMA were determined 
by monomer conversion from proton NMR and end-group analysis, respectively. In addition, the brushes could be dissolved in 1, 2-dichlorobenzene, and thus tapping-mode AFM was used to image the morphologies of oligothiophene-containing polymer brushes. The representative image of $\mathrm{PN}_{127}-g$-PTTEMA 29 (Figure S4) exhibited a wormlike morphology, similar to many other molecular brushes, mainly due to long persistent length imparted from densely grafted side chains. Therefore, all results demonstrated the successful execution for each synthetic step to obtain PN-g-PTTEMA polymer brushes.

Scheme 1. Synthesis of terthiophene-containing polymer brushes by a combination of ROMP and RAFT polymerization.

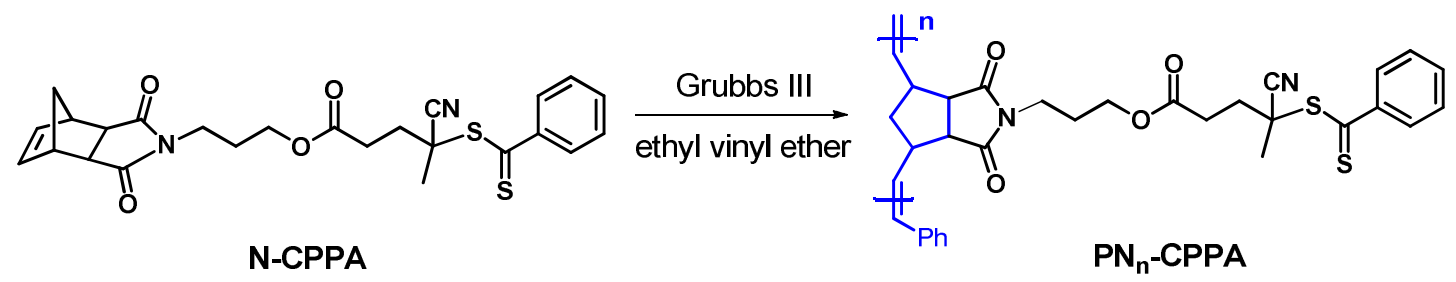

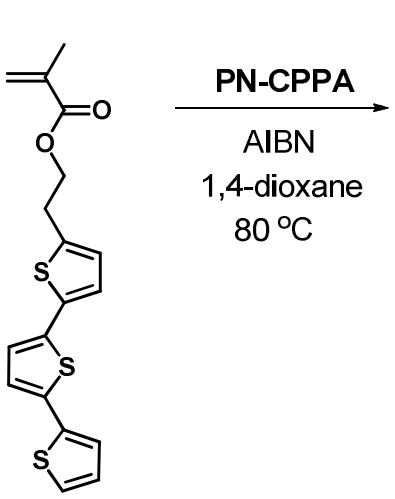

TTEMA

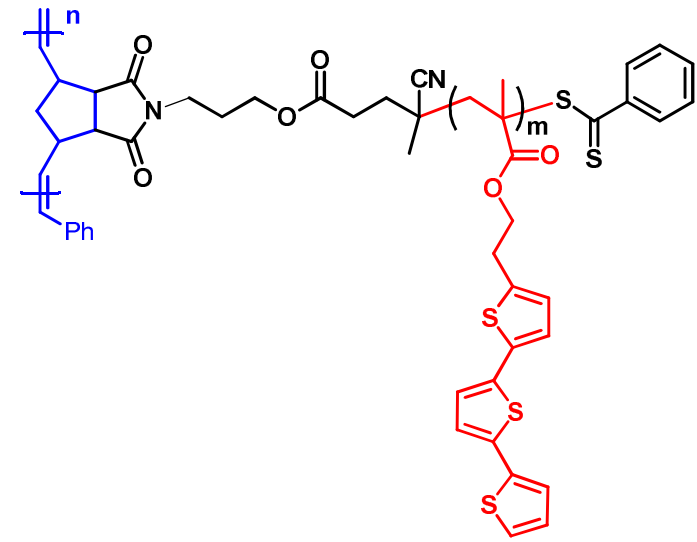

$\mathrm{PN}_{\mathrm{n}}$-g-PTTEMA 


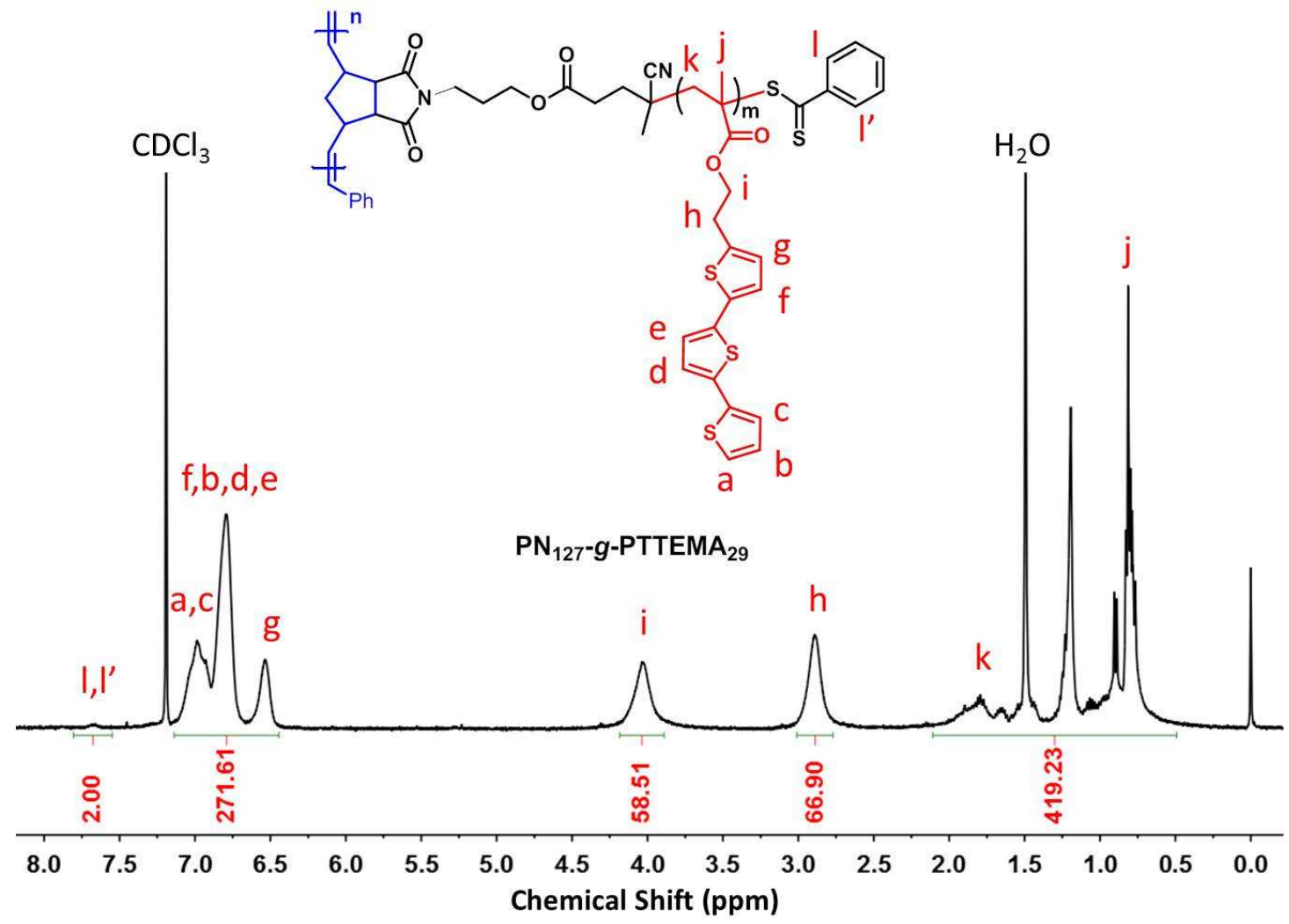

Figure 1. Representative ${ }^{1} \mathrm{H}$ NMR spectrum of terthiophene-containing polymer brush $\mathrm{PN}_{127}-g-\mathrm{PTTEMA}_{29}$.

Table 1. Molecular weight information and thermal properties of polymer brushes.

\begin{tabular}{|c|c|c|c|c|c|c|c|}
\hline $\begin{array}{c}\text { Polymer } \\
\text { Brushes }\end{array}$ & $\mathrm{n}^{\mathrm{a}}$ & $\mathrm{m}^{\mathrm{a}}$ & $\begin{array}{c}M_{\mathrm{n}}^{\mathrm{b}} \\
\left(\mathrm{g} \mathrm{mol}^{-1}\right)\end{array}$ & $\begin{array}{c}T_{\text {recryst }} \\
\left({ }^{\circ} \mathrm{C}\right)\end{array}$ & $\begin{array}{c}-\Delta H_{c}^{\mathrm{c}} \\
\left(\mathrm{J} \mathrm{g}^{-1}\right)\end{array}$ & $\begin{array}{c}T_{\mathrm{m} . \mathrm{p} .} \\
\left({ }^{\circ} \mathrm{C}\right)\end{array}$ & $\begin{array}{c}-\Delta H_{m}{ }^{\mathrm{d}} \\
\left(\mathrm{J} \mathrm{g}^{-1}\right)\end{array}$ \\
\hline PN $_{\mathbf{1 2 7}} \mathbf{g}$-PTTEMA 29 & 127 & 29 & $1,389,100$ & 104.6 & 18.88 & 124.4 & 15.51 \\
\hline PN $_{\mathbf{1 2 7}} \mathbf{g}$-PTTEMA & 127 & 38 & $1,801,100$ & 108.2 & 19.53 & 127.7 & 16.43 \\
\hline
\end{tabular}

${ }^{a}$ For both polymer brushes, the DPs of backbone PN and side chain PTTEMA are determined by monomer conversion from ${ }^{1} \mathrm{H}$ NMR. For side chain PTTEMA, DP determined by end-group analysis was consistent with that obtained from ${ }^{1} \mathrm{H}$ NMR. ${ }^{b}$ Calculation following the DP shown in note $a .{ }^{\mathrm{c}} \Delta H_{c}$ is the enthalpy of crystallization process. ${ }^{\mathrm{d}} \Delta H_{m}$ is the enthalpy of the fusion of the melting transition. 


\subsection{Thermal Properties and Crystalline Structures}

Thermogravimetric analysis (TGA, Figure S5) was carried out to evaluate the thermal stability for these oligothiophene-containing polymer brushes. The thermal decomposition onset temperature was at $271{ }^{\circ} \mathrm{C}$ and $276{ }^{\circ} \mathrm{C}$ with $5 \%$ weight loss for $\mathrm{PN}_{127^{-}} g-\mathrm{PTTEMA}_{29}$ and $\mathrm{PN}_{127^{-}} g-\mathrm{PTTEMA}_{38}$, respectively. The results indicated they possess good thermal stability, desirable for durable capacitor applications.

Differential scanning calorimetry (DSC) and Wide-angle X-ray diffraction (WAXD) measurements were performed to estimate the microstructure of polymer brushes. As shown in Figure 2, DSC curves show distinct melting and crystallization processes for both polymer brushes. The crystallization temperature slightly increased with the increase of molecular weight, from $104.6{ }^{\circ} \mathrm{C}$ for $\mathrm{PN}_{127}-g$-PTTEMA 29 to $108.2{ }^{\circ} \mathrm{C}$ for $\mathrm{PN}_{127}$ g-PTTEMA 38 (data shown in Table 1). Additionally, the melting points showed similar tendency with the change of molecular weight. As shown in Table 1, the $\Delta H_{m}$ value of $\mathrm{PN}_{127^{-} g \text {-PTTEMA }}$ PT $\left(16.43 \mathrm{~J} \mathrm{~g}^{-1}\right)$ is higher than that of $\mathrm{PN}_{127}-g$-PTTEMA 29 $\left(15.51 \mathrm{~J} \mathrm{~g}^{-1}\right)$, indicating that the degree of crystallinity of polymer brush with higher molecular weight (longer side chain PTTEMA) should be higher than that with lower molecular weight (shorter side chain PTTEMA). These results suggested that the interaction between terthiophene side-chains might induce the formation of crystalline domains, given the presence of amorphous PN and graft PTTEMA methacrylate backbones. 


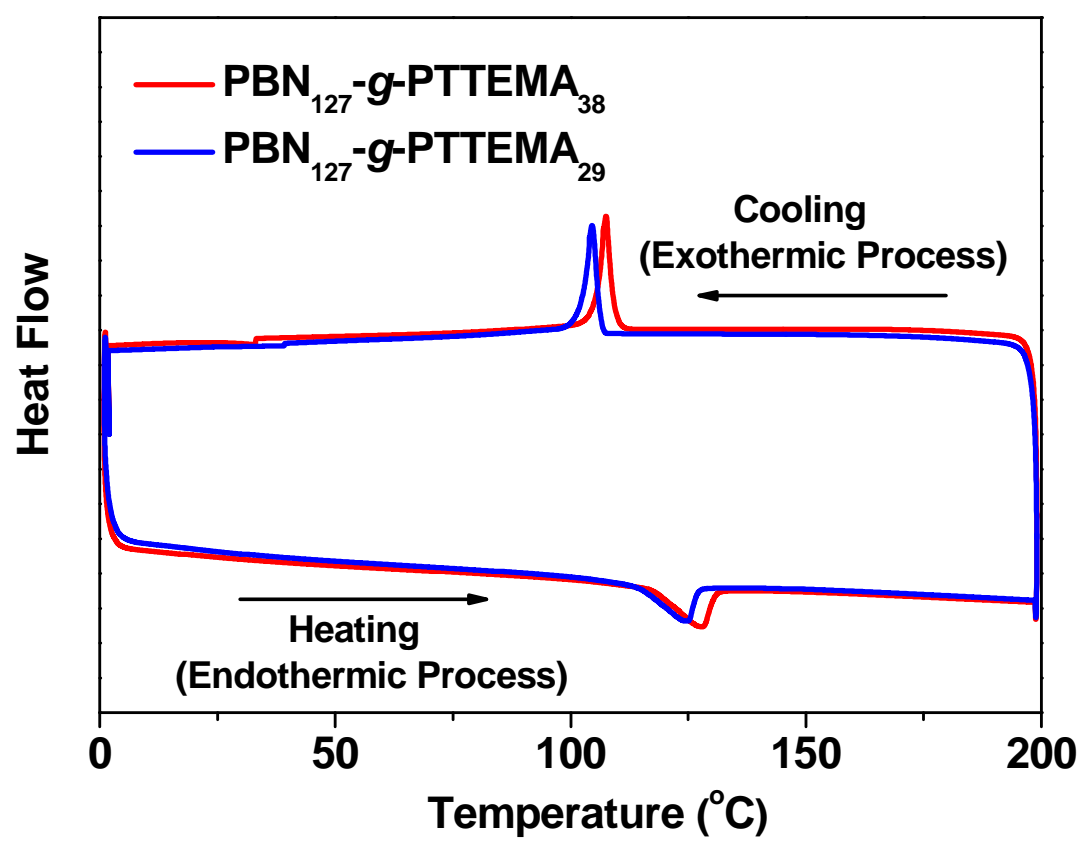

Figure 2. DSC profiles of terthiophene-containing polymer brushes (second heating and cooling cycle).

As shown in Figure 3, the WAXD profiles of both polymer brushes showed similar diffraction patterns to those for previously reported terthiophene-containing PTTEMA homopolymers: $:^{37}$ a relatively strong diffraction peak at a $2 \theta$ angle of ca. $19^{\circ}$ with two much weaker high-order peaks located at ca. $28^{\circ}$ and ca. $39^{\circ}$ respectively. The asymmetric and rather sharp main peak implied that it should be diffraction from a mixture of crystalline and amorphous structures. There are four peaks for each polymer brush by further deconvolution of WAXD profiles $\left(18.48^{\circ}, 19.12^{\circ}, 28.04^{\circ}\right.$ and $39.92^{\circ}$ for $\mathrm{PN}_{127^{-}}$- PTTEMA $_{29} ; 19.16^{\circ}, 19.20^{\circ}, 28.40^{\circ}$ and $38.48^{\circ}$ for $\mathrm{PN}_{127^{-}}$-PTTEMA 38 ). It was suggested that the sharpest peaks at $19.12^{\circ}$ and $19.20^{\circ}$ originates from crystalline domains of $\mathrm{PN}_{127}-g-\mathrm{PTTEMA}_{29}$ and $\mathrm{PN}_{127}-g-\mathrm{PTTEMA}_{38}$, respectively. Meanwhile, the other three broad peaks for each sample come from amorphous structures, which are 
associated with poly(methyl methacrylate)-like polymer backbone. ${ }^{53}$ Moreover, the degree of crystallization could be calculated based on fraction of areas under crystalline peaks in the total areas under both crystalline and amorphous regions of homopolymers. Consequently, the degree of crystallization is approximately $12.4 \%$ and $17.8 \%$ for $\mathrm{PN}_{127}-g$-PTTEMA 29 and $\mathrm{PN}_{127}-g$-PTTEMA 38 , respectively. This agrees with the trend in the DSC data, which indicates a higher degree of crystallinity (based on $\Delta H_{m}$ ) for $\mathrm{PN}_{127}-g$-PTTEMA 38 .

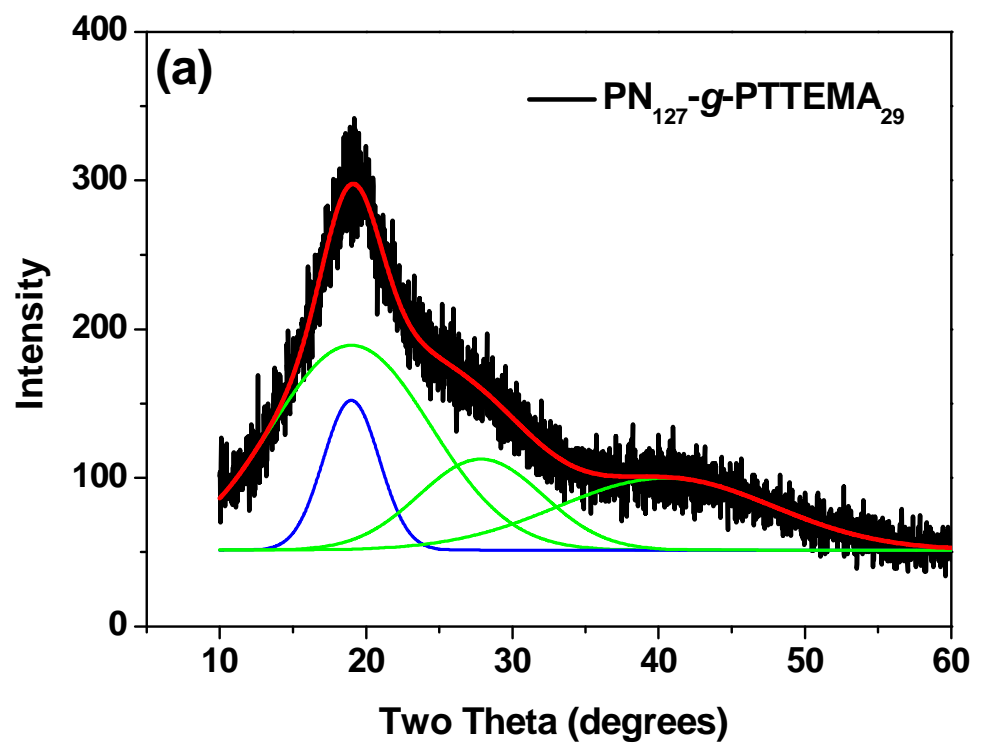




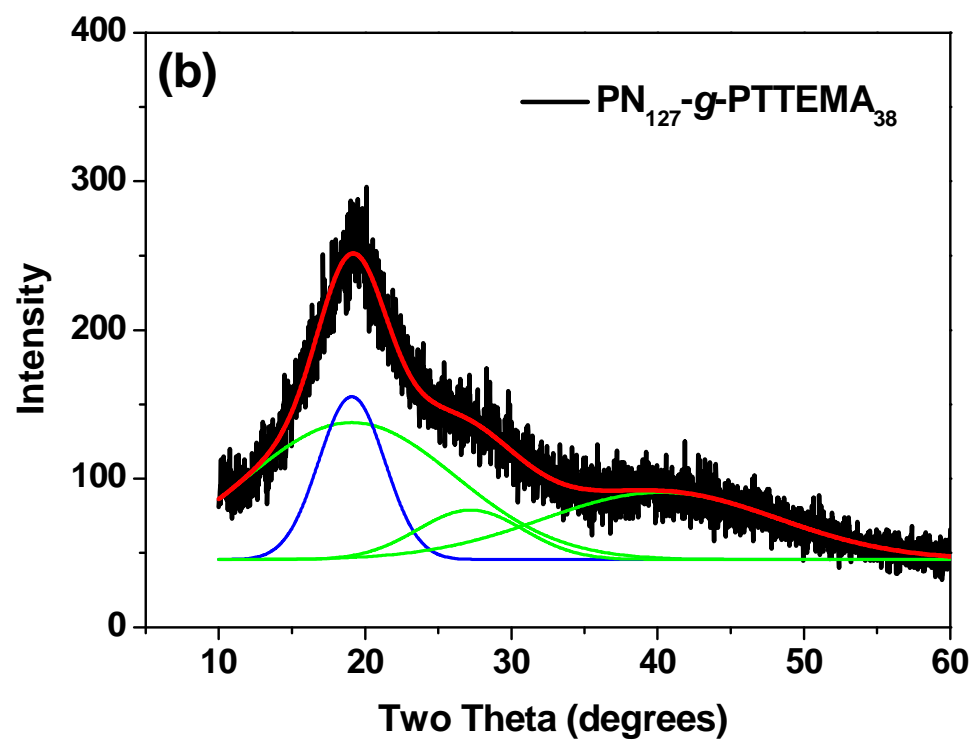

Figure 3. WXRD patterns of terthiophene-containing polymer brushes (black line: experimental data; red line: fitting sum peak; blue and green lines: fitting multi-peaks).

Additionally, the crystalline domain size can be estimated from the Scherrer's formula: ${ }^{54,55} t=\lambda / B \cos \theta$, where $t$ is the crystallite size, $\lambda \lambda$ is the wavelength of $\mathrm{X}$-ray, $B$ is the full width at half-maximum of diffraction peaks, and $\theta$ is the diffraction angle. Accordingly, the crystalline domain size is ca. $1.98 \mathrm{~nm}$ and $1.69 \mathrm{~nm}$ for $\mathrm{PN}_{127^{-}} g-\mathrm{PTTEMA}_{29}$ and $\mathrm{PN}_{127^{-}} g$-PTTEMA 38 , respectively. Compared with the PTTEMA homopolymers, the inclusion of PN backbone has little effect on the formation of small nanoscale crystalline domains. We believe that the formation of such remarkably small crystalline domains is probably attributed to the partially interacted and self-organized pendant terthiophene groups in the side chain PTTEMA.

\subsection{Dielectric Properties}

The dielectric response of terthiophene-containing polymer brushes was characterized as a function of frequency. As shown in Figure 4, both polymer brushes 
showed almost constant relative permittivity over a wide range of frequencies from 3000 $\mathrm{Hz}$ to $4 \mathrm{MHz}$. Over this frequency range, the permittivity value of $\mathrm{PN}_{127}-g-\mathrm{PTTEMA}_{29}$ (4.08-3.94) is marginally higher than that of $\mathrm{PN}_{127^{-}}$- $-\mathrm{PTTEMA}_{38}$ (3.79-3.64); the statistical certainty of this difference is only about $76 \%$ due to low numbers of samples measured. The permittivities of these polymer brush films are low compared to those reported earlier (8-11) for PTTEMA homopolymers. ${ }^{37}$ This could be attributed to the lower overall terthiophene content in the polymer brushes (10-12 wt\%) compared to that in the PTTEMA homopolymers (67-68 wt \%). The polymer brush backbone PN-CPPA contributes a significant weight percentage in the PN-g-PTTEMA polymer brush architecture compared to the PMMA main chain moiety in the PTTEMA homopolymers. The other possible reason might be related to the decreased degree of crystallinity in the PN- $g$-PTTEMA polymer brushes (12-18\%) compared to that in PTTEMA homopolymers $(25-40 \%)$, since the crystalline domains are thought to be primarily responsible for the dielectric performance of oligothiophene-containing polymers.

As shown in Figure 5, the loss tangent for the two polymer brushes is below 0.012 over frequencies ranging from $3000 \mathrm{~Hz}$ to $2 \mathrm{MHz}(0.008-0.012$ and $0.010-0.012$ for $\mathrm{PN}_{127} g-\mathrm{PTTEMA}_{29}$ and $\mathrm{PN}_{127}-g$-PTTEMA 38 , respectively). Even at $4 \mathrm{MHz}$, the loss tangents are only 0.016 and 0.013 for $\mathrm{PN}_{127^{-}} g$-PTTEMA 29 and $\mathrm{PN}_{127}-g-\mathrm{PTTEMA}_{38}$, respectively. The low dielectric loss over such wide frequency range is noticeable, probably indicative of the adequately rapid dipole relaxation of nano-dipoles in such small crystalline domains from self-organized terthiophene groups in side chain PTTEMA. All the dielectric behaviors of oligothiophene-containing polymer brushes, especially the good consistency of permittivity and low dielectric loss over the entire measured frequency range, resemble those of the corresponding linear homopolymers. 


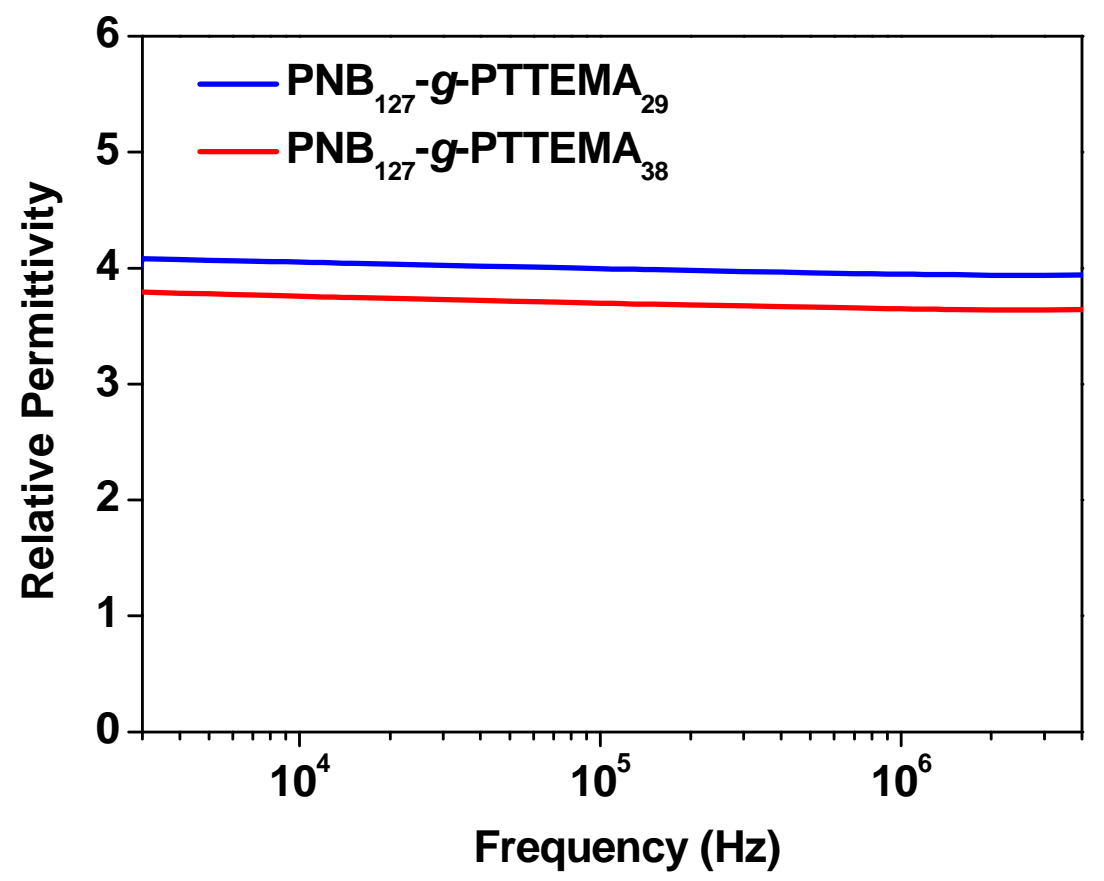

Figure 4. Relative permittivity versus frequency at ambient temperature $\left(23^{\circ} \mathrm{C}\right)$ for terthiophene-containing polymer brushes. 


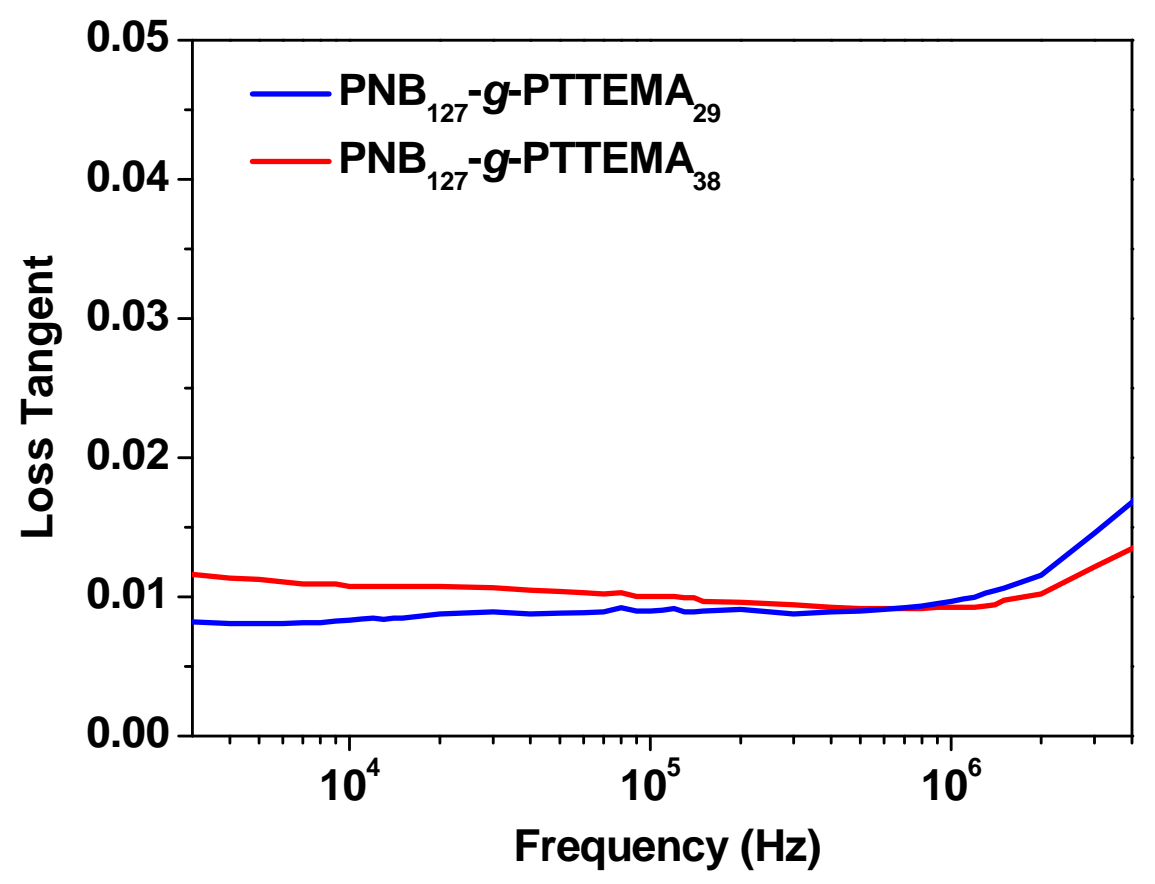

Figure 5. Loss tangent (dielectric loss) versus frequency $(1 \mathrm{KHz})$ at ambient temperature $\left(23^{\circ} \mathrm{C}\right)$ for terthiophene-containing polymer brushes.

Electric displacement-electric field $(D-E)$ hysteresis loop measurements characterize the dielectric behavior of materials at higher applied electric fields. As mentioned above, we believe that the very high molecular weight and the interactions in the side chain in the polymer brush architecture could favorably induce an improvement of mechanical properties and thus better film-forming capability compared with the corresponding linear homopolymers. Actually, free-standing films based on the polymer brushes (see inset in Figure 6) can be easily prepared via a hot-press process. As displayed in Figure 6, both terthiophene-containing polymer brushes exhibited similar linear and slim $D-E$ loops (at moderate electric field), which maintain similar behavior of corresponding linear homopolymers and resemble to the behavior of typical linear dielectric materials, such as biaxial-oriented polypropylene (BOPP), polyethylene (PE). ${ }^{5,56,57}$ Compared with the 
higher molecular weight polymer brush, the lower molecular weight polymer brush $\mathrm{PNB}_{127}{ }^{-g}$-PTTEMA 29 exhibited a larger slope of the $D-E$ loop, which is consistent with the permittivity results. Moreover, the slope of the $D-E$ loop maintained constant over the measured electric field range (e.g., up to $100 \mathrm{MV} \mathrm{m}^{-1}$ for $\mathrm{PNB}_{127^{-}} g-\mathrm{PTTEMA}_{29}$ in Figure S6). The charge displacement of $\mathrm{PNB}_{127}-g$-PTTEMA 29 was $0.49 \mu \mathrm{C} \mathrm{cm}^{-2}$ at 100 $\mathrm{MV} \mathrm{m}^{-1}$, which is lower than that of the PTTEMA homopolymers $\left(0.78-0.87 \mu \mathrm{C} \mathrm{cm}^{-2}\right.$ at $\left.100 \mathrm{MV} \mathrm{m}^{-1}\right),{ }^{37}$ but much higher than that of commercial BOPP capacitor film under the same applied electric field $\left(\sim 0.2 \mu \mathrm{C} \mathrm{cm}^{-2}\right.$ at $\left.\left.100 \mathrm{MV} \mathrm{m}^{-1}\right)\right)^{5,58}$ The small hysteresis loop further confirmed the low dielectric loss, as measured by impedance spectroscopy.

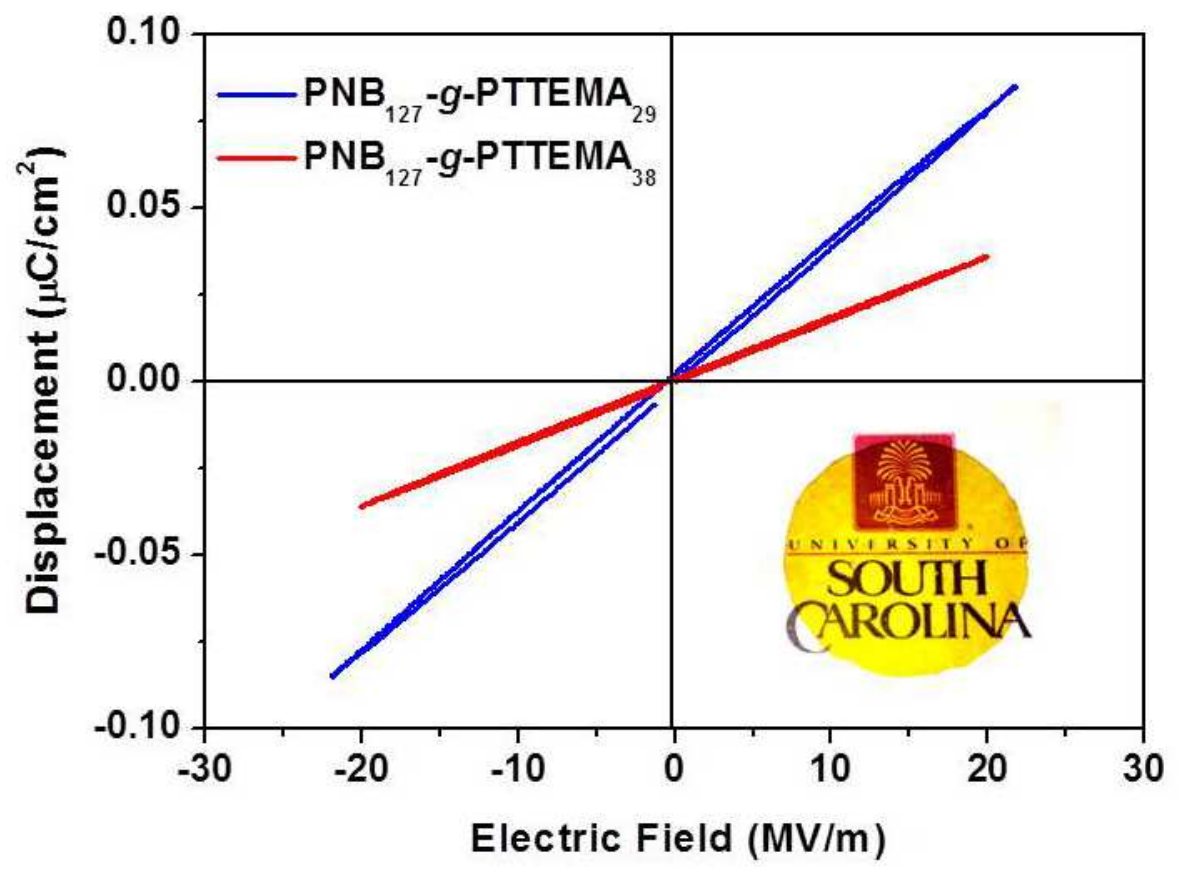

Figure 6. Electric displacement-electric field $(D-E)$ loops at ambient temperature $\left(23^{\circ} \mathrm{C}\right)$ for terthiophene-containing polymer brushes.

Figure S7 shows the energy density of polymer brush $\mathrm{PNB}_{127^{-}} g$-PTTEMA ${ }_{29}$, including stored energy density and released energy density. Estimated from the discharging cycle in Figure S6, the energy density is $0.27 \mathrm{~J} \mathrm{cc}^{-1}$ at $100 \mathrm{MV} \mathrm{m}^{-1}$, which is 
still higher than that of most linear homopolymers (such as PS, BOPP, etc.) at the same applied electric field. ${ }^{56-58}$ Considering the energy density exponentially increased with the applied electric field, we believe that there is still opportunity for further improvement of the breakdown field strength, and in turn the energy density.

\section{Conclusions}

In conclusion, we prepared oligothiophene-containing polymer brushes as novel nanodielectric materials. These polymer brushes were successfully prepared using a "grafting from" strategy via a combination of ROMP and RAFT polymerization methods.

DSC and WAXD results indicated the polymer brushes could form small nanoscale crystalline domains $(\sim 2 \mathrm{~nm})$, similar to the corresponding oligothiophene-containing homopolymers. When applied as dielectric materials in capacitors, although the permittivity decreased to nearly half of that of the homopolymers, they still exhibited good consistency of permittivity and low dielectric loss over a wide range of frequencies up to $4 \mathrm{MHz}$. In addition, it is noticeable that free-standing and transparent films could be readily fabricated based on these polymer brushes by the hot-press process and then used for dielectric studies, indicative of significantly improved film-forming capability and much easier processability due to better mechanical property of the polymer brushes in comparison with corresponding oligothiophene-containing homopolymers. The film samples of polymer brushes showed linear and reversible polarization-depolarization profiles with very low dielectric loss at moderate electric fields. Employing a polymer brush architecture is a promising chemical strategy in order to advance the development of such $\pi$-conjugated oligomer-containing dielectric materials.

\section{Acknowledgements}


This work was supported by the Office of Naval Research (award N000141110191) and SC NASA EPSCoR (award 22-NE-USC_Tang).

\section{References}

[1] Nalwa HS. Handbook of low and high dielectric constant materials and their applications. Academic Press: London, 1999.

[2] Jain P, Rymaszewski EJ. Thin film capacitors for packaged electronics. National Academics: Washington D.C., 2003.

[3] Bhattacharya SK, Tummala RR. Next generation integral passives: Materials, processes, and integration of resistors and capacitors on PWB substrates. J Mater Sci Mater Electron 2000;11:253-68.

[4] Barber P, Balasubramanian S, Anguchamy Y, Gong S, Wibowo A, Gao H, et al. Polymer composite and nanocomposite dielectric materials for pulse power energy storage. Materials 2009;2:1697-733.

[5] Zhu L, Wang Q. Novel ferroelectric polymers for high energy density and low loss dielectrics. Macromolecules 2012;45:2937-54.

[6] Thongbai P, Yamwong T, Maensiri S. Electrical responses in high permittivity dielectric (Li, Fe)-doped NiO ceramics. Appl Phys Lett 2009;94:152905.

[7] Zhu J, Jin C, Cao W, Wang X. Phase transition and dielectric properties of nanograin $\mathrm{BaTiO}_{3}$ ceramic under high pressure. Appl Phys Lett 2008;92:242901.

[8] Haeni JH, Irvin P, Chang W, Uecker R, Reiche P, Li Y, et al. Room-temperature ferroelectricity in strained $\mathrm{SrTiO}_{3}$. Nature 2004;430:758-61. 
[9] Wilk GD, Wallace RM, Anthony JM. Hafnium and zirconium silicates for advanced gate dielectrics. J Appl Phys 2000; 87:484-92.

[10]Wang Q, Zhu L. Polymer nanocomposites for electrical energy storage. J Polym Sci B Polym Phys 2011;49:1421-9.

[11]Dang Z, Yuan J, Zha J, Zhou T, Li S, Hu G. Fundamentals, processes and applications of high-permittivity polymer-matrix composites. Prog Mater Sci 2012;57:660-723.

[12]Nguema E, Vigneras V, Miane JL, Mounaix P. Dielectric properties of conducting polyaniline films by THz time-domain spectroscopy. Eur Polym J 2008;44:124-9.

[13]Fattoum A, Arous M, Gmati F, Dhaoui W, Mohamed AB. Influence of dopant on dielectric properties of polyaniline weakly doped with dichloro and trichloroacetic acids. J Phys D Appl Phys 2007;40:4347-54.

[14]Ho J, Ramprasad R, Boggs S. Effect of alteration of antioxidant by UV treatment on the dielectric strength of BOPP capacitor film. IEEE Trans Dielectr Electr Insul 2007;14:1295-301.

[15] Starkweather HW, Avakian P, Matheson RR, Fontanella JJ, Wintersgill MC. Ultralow temperature dielectric relaxations in polyolefins. Macromolecules $1992 ; 25: 6871-5$.

[16]Zhang Q, Bharti V, Zhao X. Giant electrostriction and relaxor ferroelectric behavior in electron-irradiated poly(vinylidene fluoride-trifluoroethylene) copolymer. Science $1998 ; 280: 2101-4$.

[17]Chu B, Zhou X, Ren K, Neese B, Lin M, Wang Q, et al. A dielectric polymer with high electric energy density and fast discharge speed. Science 2006;313:334-6.

[18]Xia F, Cheng Z, Xu H, Li H, Zhang Q, Kavarnos GJ, et al. High electromechanical responses in a poly(vinylidene fluoride-trifluoroethylene-chlorofluoroethylene) terpolymer. 
http://onlinelibrary.wiley.com/doi/10.1002/1521-4095(20021104)14:21\%3c1574::AID-A DMA1574\%3e3.0.CO;2-\%23/abstractAdv Mater 2002;14:1574-7.

[19]Bornand V, Vacher C, Collet A, Papet P. Interest of binary PMMA/P(VDF-TrFE) blend thin films. Mater Chem Phys 2009;117:169-72.

[20]Chu B, Neese B, Lin M, Lu S, Zhang Q. Enhancement of dielectric energy density in the poly (vinylidene fluoride)-based terpolymer/copolymer blends. Appl Phys Lett 2008; 93:152903.

[21]Li R, Xiong C, Kuang D, Dong L, Lei Y, Yao J, et al. Polyamide 11/poly (vinylidene fluoride) blends as novel flexible materials for capacitors. Macromol Rapid Commun 2008;29:1449-54.

[22]Meng Q, Li W, Zheng Y, Zhang Z. Effect of poly (methyl methacrylate) addition on the dielectric and energy storage properties of poly (vinylidene fluoride). J Appl Polym Sci 2010;116:2674-84.

[23]Rahimabady M, Yao K, Arabnejad S, Lu L, Shim VPW, Chet DCW. Intermolecular interactions and high dielectric energy storage density in poly (vinylidene fluoridehexafluoropropylene)/poly (vinylidene fluoride) blend thin films. Appl Phys Lett 2012;100:252907.

[24]Wu S, Lin M, Lu S, Zhu L, Zhang Q. Polar-fluoropolymer blends with tailored nanostructures for high energy density low loss capacitor applications. Appl Phys Lett 2011;99:132901.

[25]Zhang S, Neese B, Ren K, Chu B, Zhang Q. Microstructure and electromechanical responses in semicrystalline ferroelectric relaxor polymer blends. J Appl Phys 2006;100:044113.

[26]Chwang C-P, Liu C-D, Huang S-W, Chao D-Y, Lee S-N. Synthesis and characterization of high dielectric constant polyaniline/polyurethane blends. Synt Met 2004;142:275-81. 
[27]Guo M, Hayakawa T, Kakimoto M, Goodson T. Organic macromolecular high dielectric constant materials: Synthesis, characterization, and applications. J Phys Chem B 2011;115:13419-32.

[28]Huang C, Zhang Q, Su J. High-dielectric-constant all-polymer percolative composites. App Phys Lett 2003;82:3502-4.

[29]Huang C, Zhang Q. Enhanced dielectric and electromechanical responses in high dielectric constant all-polymer percolative composites. Adv Funct Mater 2004; 14:501-6. [30]Huang C, Zhang Q. Fully functionalized high-dielectric-constant nanophase polymers with high electromechanical response. Adv Mater 2005;17:1153-8.

[31]Huang C, Zhang Q, deBotton G, Bhattacharya K. All-organic dielectric-percolative three-component composite materials with high electromechanical response. Appl Phys Lett 2004;84:4391-3.

[32]Molberg M, Crespy D, Rupper P, Nueesch F, Manson J-AE, Loewe C, et al. High breakdown field dielectric elastomer actuators using encapsulated polyaniline as high dielectric constant filler. Adv Funct Mater 2010;20:3280-91.

[33]Zhang Q, Li H, Poh M, Xia F, Cheng Z, Xu H, et al. An all-organic composite actuator material with a high dielectric constant. Nature 2002;419:284-7.

[34]Lewis TJ. Nanometric dielectrics. IEEE Trans. Dielectr. Electr. Insul. $1994 ; 1: 812-25$.

[35]Hardy CG, Islam M, Gonzalez-Delozier $\mathrm{D}$, Ploehn HJ, Tang C. Oligoaniline-containing supramolecular block copolymer nanodielectric materials. Macromol Rapid Commun 2012;33:791-7.

[36]Hardy CG, Islam MS, Gonzalez-Delozier D, Morgan JE, Cash B, Benicewicz BC, et al. Converting an electrical insulator into a dielectric capacitor: End-capping polystyrene with oligoaniline. Chem Mater 2013;25:799-807. 
[37]Qiao Y, Islam MS, Han K, Leonhardt E, Zhang J, Wang Q, et al. Polymers containing highly polarizable conjugated side chains as high-performance all-organic nanodielectric materials. Adv Funct Mater 2013;23:5638-46.

[38]Qiao Y, Islam MS, Wang L, Yan Y, Zhang J, Benicewicz BC, et al. Thiophene polymer-grafted barium titanate nanoparticles toward nanodielectric composites. Chem Mater 2014;26:5319-26.

[39]Islam MS, Qiao Y, Tang C, Ploehn HJ. Terthiophene-containing copolymers and homopolymer blends as high performance dielectric materials. ACS Appl Mater Interfaces 2015; DOI: 10.1021/am507751m.

[40]Matyjaszewski K, Tsarevsky NV. Macromolecular engineering by atom transfer radical polymerization. J Am Chem Soc 2014;136:6513-33.

[41]Matyjaszewski K. Atom transfer radical polymerization (ATRP): Current status and future perspectives. Macromolecules 2012;45:4015-39.

[42]Matyjaszewski K, Sumerlin BS, Tsarevsky NV. Progress in controlled radical polymerization: Materials and applications. American Chemical Society: Washington, D.C., 2012.

[43]Hawker CJ, Wooley KL. The convergence of synthetic organic and polymer chemistries. Science 2005;309:1200-5.

[44]Moad G, Rizzardo E, Thang SH. Living radical polymerization by the RAFT process. Aust J Chem 2005;58:379-410.

[45]Chiefari J, Chong YK, Ercole F, Krstina J, Jeffery J, Le TPT, et al. Living free-radical polymerization by reversible addition-fragmentation chain transfer: $\square$ The RAFT process. Macromolecules 1998;31:5559-62.

[46]Schrock RR. Living ring-opening metathesis polymerization catalyzed by well-characterized transition-metal alkylidene complexes. Acc Chem Res 1990;23:158-65. 
[47]Bielawski CW, Grubbs RH. Living ring-opening metathesis polymerization. Prog Polym Sci 2007;32:1-29.

[48] Yao K, Chen Y, Zhang J, Bunyard C, Tang C. Cationic salt-responsive bottle-brush polymers. Macromol Rapid Commun 2013;34:645-51.

[49]Ren L, Zhang J, Bai X, Hardy CG, Shimizu KD, Tang C. Preparation of cationic cobaltocenium polymers and block copolymers by "living" ring-opening metathesis polymerization. Chem Sci 2012;3:580-3.

[50]Zhang J, Ren L, Hardy CG, Tang C. Cobaltocenium-containing methacrylate homopolymers, block copolymers, and heterobimetallic polymers via RAFT polymerization. Macromolecules 2012;45:6857-63.

[51]Zhang J, Pellechia PJ, Hayat J, Tang C. Quantitative and qualitative counterion exchange in cationic metallocene polyelectrolytes. Macromolecules 2013;46:1618-24.

[52]Sanford MS, Love JA, Grubbs RH. A versatile precursor for the synthesis of new ruthenium olefin metathesis catalysts. Organometallics 2001;20:5314-8.

[53]Tomar AK, Mahendia S, Kumar S. Structural characterization of PMMA blended with chemically synthesized PAni. Adv Appl Sci Res 2011;2:327-33.

[54]Li J, Khanchaitit P, Han K, Wang Q. New route toward high-energy-density nanocomposites based on chain-end functionalized ferroelectric polymers. Chem Mater 2010;22:5350-7.

[55]Zhu L, Calhoun BH, Ge Q, Quirk RP, Cheng SZD, Thomas EL, et al. Initial-stage growth controlled crystal orientations in nanoconfined lamellae of a self-Assembled crystalline-amorphous diblock copolymer. Macromolecules 2001;34:1244-51.

[56]Rabuffi M, Picci G. Status quo and future prospects for metallized polypropylene Energy Storage Capacitors. IEEE Trans Plasma Sci 2002;30:1939-42.

[57]Picci G, Rabuffi M. Pulse handling capability of energy storage metallized film capacitors. IEEE Trans Plasma Sci 2000;28:1603-6. 
[58]Chung TCM. Functionalization of polypropylene with high dielectric properties: Applications in electric energy storage. Green Sustainable Chem 2012;2:29-37.

\section{TOC Graphic}

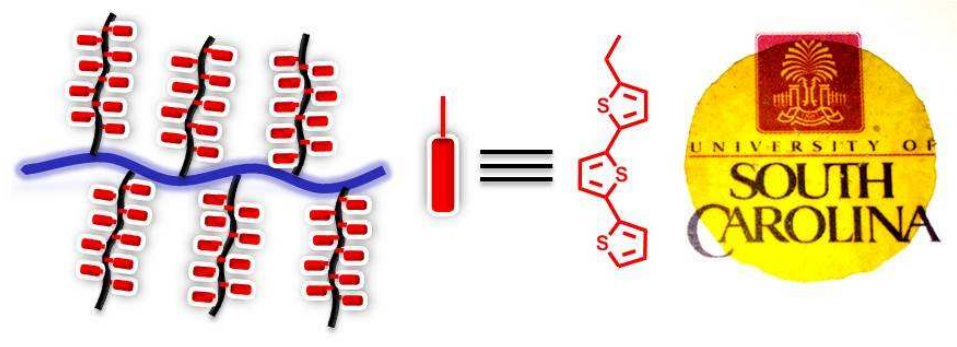

